\title{
Predictive values of two frailty screening tools in older patients with solid cancer: a comparison of SAOP2 and G8
}

\author{
Chiara Russo ${ }^{1, *}$, Chiara Giannotti ${ }^{1, *}$, Alessio Signori ${ }^{2}$, Michele Cea ${ }^{1}$, Roberto \\ Murialdo ${ }^{1}$, Alberto Ballestrero ${ }^{1}$, Stefano Scabini ${ }^{3}$, Emanuele Romairone ${ }^{3}$, Patrizio \\ Odetti $^{1}$, Alessio Nencioni ${ }^{1}$ and Fiammetta Monacelli ${ }^{1}$ \\ ${ }^{1}$ Department of Internal Medicine and Medical Specialties (DIMI), Section of Geriatrics, Genoa, Italy \\ ${ }^{2}$ DISSAL, Section of Biostatistics, Department of Health Sciences, University of Genova, Genoa, Italy \\ ${ }^{3}$ Hospital Policlinic San Martino, Oncological Surgery and Implantable Systems, Genoa, Italy \\ *These authors have contributed equally to this work \\ Correspondence to: Fiammetta Monacelli, email: fiammetta.monacelli@unige.it \\ Keywords: aging; cancer; screening tool; geriatric assessment; frailty \\ Received: April 19, $2018 \quad$ Accepted: September 01, $2018 \quad$ Published: October 12, 2018 \\ Copyright: Russo et al. This is an open-access article distributed under the terms of the Creative Commons Attribution License 3.0 \\ (CC BY 3.0), which permits unrestricted use, distribution, and reproduction in any medium, provided the original author and source \\ are credited.
}

\section{ABSTRACT}

Objectives: Comprehensive Geriatric Assessment (CGA), the gold standard for detecting frailty in elderly cancer patients, is time-consuming and hard to apply in routine clinical practice. Here we compared the performance of two screening tools for frailty, $\mathbf{6 8}$ and SAOP2 for their accuracy in identifying vulnerable patients.

Material and Methods: We tested G8 and SAOP2 in 282 patients aged 65 or older with a diagnosis of solid cancer and candidate to undergo surgical, medical and/or radiotherapy treatment. CGA, including functional and cognitive status, depression, nutrition, comorbidity, social status and quality of life was used as reference. ROC curves were used to compare two screening tools.

Results: Mean patient age was 79 years and $54 \%$ were female. Colorectal and breast cancer were the most common types cancer ( $49 \%$ and $24 \%)$. Impaired CGA, G8, and SAOP2 were found in $62 \%, 89 \%$, and $94 \%$ of the patients, respectively. SAOP2 had a better sensitivity (AUC 0.85 , p<0.032) than G8 (AUC 0.79), with higher performance in breast cancer patients (AUC 0.93) and in patients aged 70-80 years (AUC 0.87).

Conclusions: G8 and SAOP2 both showed good screening capacity for frailty in the cancer patient population we examined with SAOP2 showing a slightly better performance than G8.

\section{INTRODUCTION}

The risk of cancer increases with age [1]. Already as of today, more than half of the patients who are newly diagnosed with cancer are older than 65 and this percentage is projected to increase to $70 \%$ by 2030 [2, 3]. This "oncogeriatric" population will benefit from the development of innovative therapies or surgical procedures, which will, however, require specific clinical management [4].
Despite the increasing rate of elderly cancer patients, there is a major gap of knowledge on how to properly stratify older patients according to their biological status, to be able to recommend the most appropriate type of treatment in a personalized fashion.

The Comprehensive Geriatric Assessment (CGA) is a multidimensional, interdisciplinary evaluation that leads to the identification and stratification of patients' clinical vulnerability. 
According to the International Society of Geriatric Oncology (SIOG), the CGA remains the gold standard for defining the presence and or the degree of frailty in elderly cancer patients; its widespread use is recommended, particularly since the CGA was shown to improve patient overall survival, functional status, and quality of life $[5,6]$. In geriatric oncology frailty's evaluation is mainly focused on person's ability to tolerate cancer treatment; frailty is also associated with a worse quality of life.

However, the CGA is time and resource-consuming and requires the expertise of geriatricians who are not always available in standard cancer clinics. It remains poorly incorporated in routine clinical practice. Thus, consensus guidelines from the National Comprehensive Cancer Network (NCCN) [7], the European Organization for Research and Treatment of Cancer (EORTC) [8], and the SIOG [9], consider a "two-step approach" as a reasonable strategy, where the first step involves a geriatric screening test to identify patients who are at high risk of being frail and the second step foresees a complete CGA to be performed by geriatricians [1, 10-13].

Since the 2005 SIOG guidelines, a total of 17 different tools have been studied in 44 different trials to evaluate the best screening test in oncogeriatrics [9]. These include G8, Oncogeriatric screen (OGS), Abbreviated Comprehensive Geriatric Assessment (aCGA), Senior
Adult Oncology Program (SAOP) 2, Gerhematolim, the Vulnerable Elders Survey-13 (VES-13) and Flemish version of the Triage Risk Screening Tool (fTRST) [9].

So far, although the G8, the VES-13 and fTRST tools have shown the best clinometric properties in elderly patients [9], there remains a substantial uncertainty as to which test most adequately identifies frailty in at risk older cancer populations [14].

The purpose of this study was to define the accuracy with which two geriatric screening tools, G8 and SAOP2 identify frail oncogeriatric patients, who are ultimately candidates to receive a CGA.

\section{RESULTS}

\section{Patients' clinical characteristics}

Three hundred three eligible cancer patients were evaluated at the Ospedale Policlinico San Martino in Genoa, Italy, between January 2015 and May 2017. For two patients, clinical data collection was not completed and therefore they were not included in the study. Nineteen patients did not meet the inclusion criteria. Thus, 282 eligible patients were evaluated in the study (Figure 1). Mean patient's age was 79.02 years \pm 5.87 (range, 6593 years) and about $40 \%$ of the patients were $>80$ years

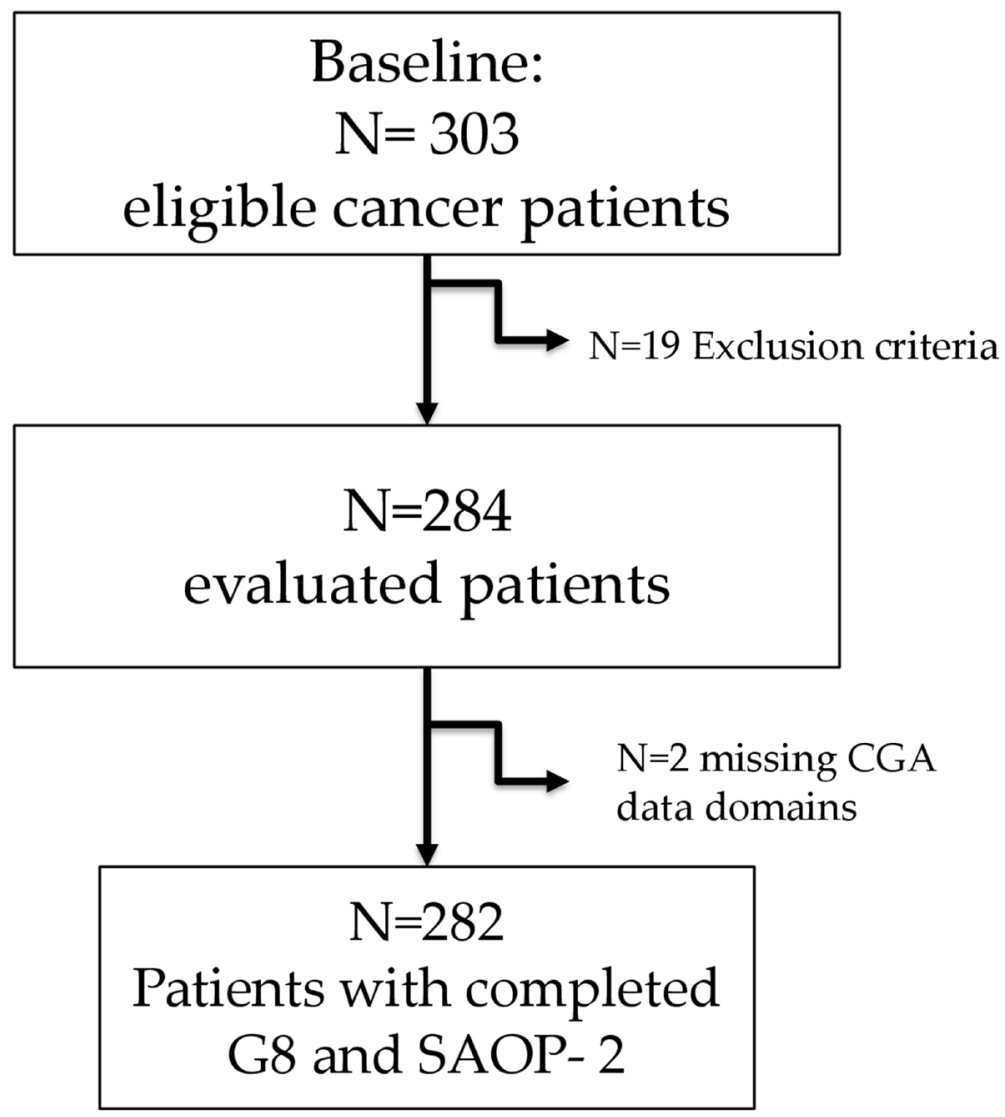

Figure 1: Study sample design. 
Table 1: Patients' demographic and clinical characteristics

\begin{tabular}{|c|c|}
\hline VARIABLE & $\mathbf{N}$ \\
\hline \multicolumn{2}{|l|}{ DEMOGRAPHICS } \\
\hline \multicolumn{2}{|l|}{ GENDER: } \\
\hline FEMALE & 152 \\
\hline MALE & 130 \\
\hline$M E A N A G E$ & $79.02 \pm 5.87$ (range $65-93$ YEARS) \\
\hline \multicolumn{2}{|l|}{$A G E$} \\
\hline$<69$ & 14 \\
\hline $70-80$ & 156 \\
\hline $81-89$ & 101 \\
\hline$>90$ & 11 \\
\hline \multicolumn{2}{|l|}{ CANCER TYPE } \\
\hline COLORECTAL & 138 \\
\hline GASTRIC AND OESOPHAGEAL & 15 \\
\hline PANCREAS AND BILIAR TRACT & 4 \\
\hline HEAD AND NECK & 12 \\
\hline BREAST & 68 \\
\hline PROSTATE & 11 \\
\hline GYNAECOLOGICAL & 11 \\
\hline RENAL AND BLADDER & 11 \\
\hline$L U N G$ & 3 \\
\hline OTHERS & 9 \\
\hline \multicolumn{2}{|l|}{ DISEASE STAGE } \\
\hline NON-METASTATIC DISEASE & 186 \\
\hline METASTATIC DISEASE & 14 \\
\hline UNCLASSIFIED & 82 \\
\hline
\end{tabular}

old. $54 \%$ of the patients were female and $46 \%$ were male. Colorectal cancer and breast cancer were the most common types of neoplasms for which patients were being treated, accounting for $50 \%$ and $24 \%$ of the patients, respectively.

Patients' clinical characteristics, screening tools and CGA assessment are illustrated in Table 1 and 2.

Overall, 175 out of 282 patients (62\%) showed problems in at least 3 CGA clinical domains, thus resulting as frail. This clinical vulnerability was mainly characterized by multimorbidity, initial functional decline and malnutrition risk (Table 2). In addition, patients reported a poor perception of the quality of life according to Short Form 36 (SF-36).

Notably, based on the CGA assessment, a G8 impairment mostly reflected an increased malnutrition risk (Mini Nutritional Assessment-MNA) (U 642, p<0.05) (Table 3).
Frail patients (based on CGA assessment) scored positive according to G8 in $89 \%$ and to SAOP2 in $94 \%$ of the cases, respectively (Table 4).

The comparison between G8 and SAOP2 diagnostic accuracy showed that SAOP2 had fair specificity, lower than G8.

A pairwise comparison between SAOP2 $(n=282$; AUC 0.85; 95\% CI: 0.0215-0.81130) and G8 $(n=282$; AUC 0.79 ; 95\% CI: $0.0260-0.74478$ ) with reference to CGA using ROC curves showed a higher accuracy in differentiating patients with abnormal CGA for the SAOP2 screening tool $(\mathrm{p}<0.032)$ (Figure 2$)$.

The diagnostic accuracy of both screening tools (with reference to CGA) was further assessed, separately, in patients with a diagnosis of breast cancer $(n=68)$ versus patients with a diagnosis of colorectal cancer $(n=138)$. 
Table 2: G8, SAOP2 screening tools, CGA assessment with frequency of elders who were categorized as impaired in each domains of CGA

\begin{tabular}{|c|c|c|c|c|}
\hline $\begin{array}{l}\text { SCREENING TOOLS AND } \\
\text { CGA ASSESSMENT }\end{array}$ & CLINICAL DOMAIN & CUT-OFF * & $\begin{array}{l}\text { IMPAIRED } \\
\%\end{array}$ & MEAN SCORE \pm SD \\
\hline$G 8$ & & $\leq 14$ & 74 & $12.23 \pm 2.75$ \\
\hline$S A O P 2$ & & $>2$ & 78 & $2.73 \pm 1.32$ \\
\hline$M M S E$ & COGNITIVE STATUS & $<24$ & 20 & $26.65 \pm 3.88$ \\
\hline CDT (SCHULMAN) & COGNITIVE STATUS & $\geq 3$ & 48 & $2.54 \pm 1.40$ \\
\hline$M N A$ & $\begin{array}{l}\text { NUTRITIONAL } \\
\text { STATUS }\end{array}$ & $<23$ & 44 & $22.62 \pm 3.91$ \\
\hline$I A D L$ & $\begin{array}{l}\text { FUNCTIONAL } \\
\text { STATUS }\end{array}$ & $\leq 7$ & 39 & $6.83 \pm 2.02$ \\
\hline BARTHEL INDEX & $\begin{array}{l}\text { FUNCTIONAL } \\
\text { STATUS }\end{array}$ & $<50$ & 3,5 & $95.98 \pm 11.64$ \\
\hline $\begin{array}{l}\text { CIRS } \\
\text { COMORBIDITY } \\
\text { SEVERITY }\end{array}$ & COMORBIDITY & $>3$ & 63 & $\begin{array}{l}4.23 \pm 1.83 \\
1.96 \pm 0.38\end{array}$ \\
\hline$N^{\circ} O F D R U G S$ & - & $\geq 3$ & 57 & $4.48 \pm 2.75$ \\
\hline$G D S$ & $\begin{array}{l}\text { PSYCHOLOGICAL } \\
\text { STATUS }\end{array}$ & $\geq 5$ & 30 & $3.92 \pm 3.34$ \\
\hline TINETTI SCALE & $\begin{array}{l}\text { POSTURAL } \\
\text { STABILITY }\end{array}$ & $\leq 18$ & 16,5 & $24.02 \pm 5.74$ \\
\hline MORSE SCALE & RISK OF FALL & $\geq 25$ & 29 & $23.44 \pm 19.94$ \\
\hline GIJON SCALE & SOCIAL STATUS & $\geq 10$ & 35 & $8.77 \pm 2.29$ \\
\hline$S F-36$ & QoL & & & $0.68 \pm 0.21$ \\
\hline CUT OFF CGA $A^{* *}$ & & $\geq 3$ & 62 & $3.77 \pm 2.56$ \\
\hline
\end{tabular}

Abbreviations: SAOP2: Senior Adult Oncology Program (SAOP) 2; MMSE: Mini Mental State Examination; CDT: Clock Drawing Test; MNA: Mini Nutritional Assessment ; I-ADL: Instrumental Activities of Daily Living; CIRS: Cumulative Illness Rating Scale; GDS: Geriatric Depression Scale; SF-36: Short Form 36; QoL: Quality of life; CGA: Comprehensive Geriatric Assessment.

${ }^{*}$ Cut-off score.

** cumulative number of impaired CGA domains.

The SAOP2 showed higher accuracy in predicting patients' clinical vulnerability in breast cancer patients $(\mathrm{n}=$ 68; AUC 0.93; 95\% CI: 0.87822-0.98518) as compared to the G8 ( $\mathrm{n}=68$; AUC 0.79; CI: 0.68674-0.89719) $(\mathrm{p}<0.014)$. Conversely, a comparison between SAOP2 and G8 in colorectal cancer patients did not show any difference in the ability to detect frail patients $(p<0.160)$ (Figure 3).

In addition, in patients aged between 70 and 80 years, SAOP2's diagnostic accuracy $(n=156$; AUC 0.87; 95\% CI 0.82061-0.92710) was higher as compared to G8's accuracy $(n=156$; AUC 0.77; 95\%CI 0.70043-0.84865) $(\mathrm{p}<0.015)$.
Notably, both screening tools failed to accurately detect frailty in patients aged $>80$, with a high rate of false positive results $(\mathrm{p}<0.40)$ (Figure 4$)$.

\section{DISCUSSION}

The integration of CGA in clinical practice could help oncologists tailor clinical decisions based on the elderly patient's actual fitness. Currently, a twostep approach is recommended. Nevertheless, the best screening tool to be applied in the clinic remains to be defined [14].

To the best of our knowledge, this is the first study to directly compare the performance of two commonly 
Table 3: Comparison of CGA domains in patients aged between 70 and 80 years with impaired G8 and SAOP2, respectively

\begin{tabular}{|c|c|c|c|c|}
\hline $\begin{array}{l}\text { CLINICAL DOMAIN } \\
\text { AND TOOL } \\
\text { MEAN SCORE }( \pm \text { SD }) \\
\end{array}$ & N 156 & $\begin{array}{c}\text { G8 } \leq 14 \\
\text { N } 114\end{array}$ & $\begin{array}{c}\text { SAOP } \geq 2 \\
\text { N } 131\end{array}$ & P value ${ }^{b}$ \\
\hline $\begin{array}{l}\text { COGNITIVE STATUS } \\
\text { MMSE }\end{array}$ & $27.29 \pm 2.95$ & $26.93 \pm 3.25$ & $26.85 \pm 3.16$ & ns \\
\hline $\begin{array}{l}\text { FUNCTIONAL STATUS } \\
\text { BARTHEL }\end{array}$ & $97.01 \pm 9.48$ & $95.75 \pm 11.47$ & $96.03 \pm 10.75$ & ns \\
\hline $\begin{array}{l}\text { FUNCTIONAL STATUS } \\
\text { IADL }\end{array}$ & $7.16 \pm 1.67$ & $6.83 \pm 1.95$ & $6.91 \pm 1.86$ & ns \\
\hline $\begin{array}{l}\text { PHYSICAL PERFORMANCE } \\
\text { TUG }\end{array}$ & $10.15 \pm 4.27$ & $10.80 \pm 4.87$ & $10.77 \pm 4.60$ & ns \\
\hline $\begin{array}{l}\text { NUTRITIONAL STATUS } \\
\text { MNA }\end{array}$ & $22.53 \pm 4.91$ & $20.85 \pm 4.76$ & $21.76 \pm 4.88$ & $\mathrm{U} 642, \mathrm{p}<0.05$ \\
\hline $\begin{array}{l}\text { PSYCHOLOGICAL STATUS } \\
\text { GDS }\end{array}$ & $3.89 \pm 3.44$ & $4.45 \pm 3.70$ & $4.54 \pm 3.62$ & ns \\
\hline $\begin{array}{l}\text { SOCIAL STATUS } \\
\text { GIJON SCALE }\end{array}$ & $8.53 \pm 2.36$ & $8.99 \pm 2.44$ & $9.02 \pm 2.39$ & ns \\
\hline $\begin{array}{l}\text { COMORBIDITY } \\
\text { CIRS CI }\end{array}$ & $4.05 \pm 1.83$ & $4.43 \pm 1.91$ & $4.40 \pm 1.85$ & ns \\
\hline $\begin{array}{l}\text { QOL } \\
\text { SF-36 }\end{array}$ & $0.69 \pm 0.21$ & $0.65 \pm 0.22$ & $0.65 \pm 0.22$ & ns \\
\hline
\end{tabular}

${ }^{\mathrm{b}}$ non-parametric Mann-Whitney U test.

Abbreviations: CGA: Comprehensive Geriatric Assessment; SAOP2: Senior Adult Oncology Program (SAOP) 2; MMSE:

Mini Mental State Examination; I-ADL: Instrumental Activities of Daily Living; TUG: Timed "Up \& Go" test; MNA: Mini

Nutritional Assessment; GDS: Geriatric Depression Scale; CIRS: Cumulative Illness Rating Scale; CI: Co-morbidity Index;

QoL: Quality of life; SF-36: Short Form 36.

applied frailty screening tools, G8 and SAOP2, in an older cancer population.

Clearly, a high sensitivity and specificity are both desired properties of an oncogeriatric-screening tool, to limit the number of fit patients who unnecessarily undergo CGA assessment. These clinometric properties also ensure that frailty is properly recognized, thus avoiding that vulnerable subjects are over treated and exposed to the risk of treatment toxicity [9].

Our data show that the SAOP2 has higher diagnostic accuracy as compared to the G8, especially in oncogeriatric patients who are $<80$ years. Conversely, both SAOP2 and G8 showed adequate sensitivity at the expense of specificity in patients older than 80 years. Furthermore, our results indicate that the SAOP2 screening tool has better screening performance than the G8 in breast cancer patients, but not in patients diagnosed with colorectal cancer.

Evidence is accumulating on the role of G8 screening tool in detecting vulnerable patients, even if with heterogeneous results $[9,15]$. The ONCODAGE multicentre study [16] has validated the G8 for the identification of older cancer patients eligible for CGA assessment: sensitivity varied according to tumour site and stage (head and neck cancer $94 \%$; colon cancer $88 \%$; metastatic stages $87 \%$ ). Further, Kenis et al [13] has shown high sensitivity and moderate negative predictive value of the G8 tool in elders with metastatic breast and colorectal cancer.

Conversely, the comparison among fTRST, G8, and Groningen Frailty Index in elderly cancer patients [17] has resulted in the higher diagnostic accuracy of fTRST (sensitivity 92\%) compared to G8 (sensitivity 80\%). Baitar et al [18] has confirmed the higher accuracy of G8 tool in identifying vulnerable cancer patients with prevalent malnutrition.

Furthermore, in neck and head cancer patients, the G8 tool has shown better sensitivity, compared to VES-13 [19], and, similarly, Liu et al [20] has reported G8 higher 
Table 4: Comparison between G8 and SAOP2 diagnostic accuracy with reference to the gold standard CGA

\begin{tabular}{lcccc}
\hline & Sensitivity & Specificity & PPV & NPV \\
\hline G8 & $89 \%$ & $49.5 \%$ & $73.9 \%$ & $73.6 \%$ \\
SAOP2 & $94 \%$ & $46.9 \%$ & $74 \%$ & $81 \%$ \\
\hline
\end{tabular}

Abbreviations: CGA: Comprehensive Geriatric Assessment; SAOP2: Senior Adult Oncology Program (SAOP) 2; PPV: positive predictive value; NPV: negative predictive value.

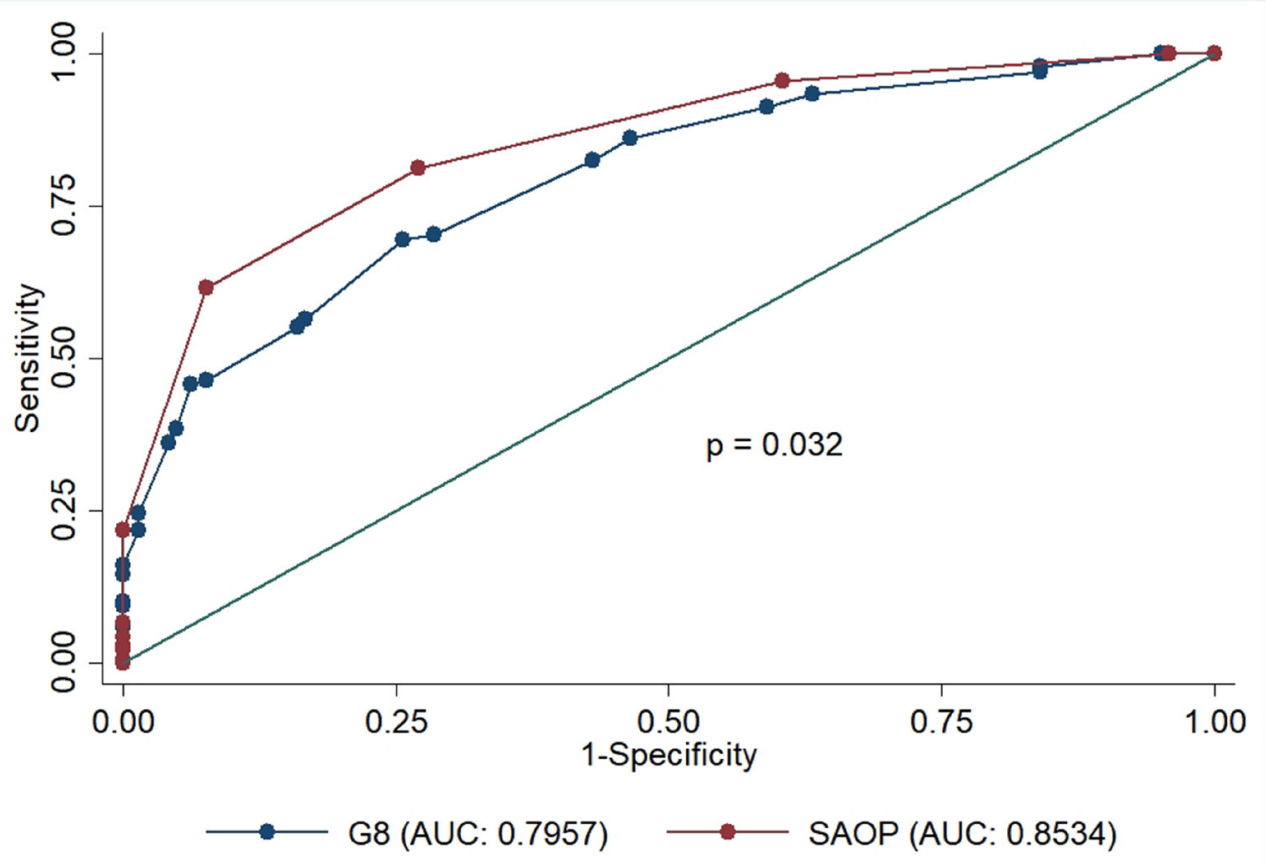

Figure 2: ROC curve diagnostic accuracy comparison between G8 and SAOP2 screening tools with reference to CGA. Abbreviations: ROC: Receiver operating characteristic; SAOP2: Senior Adult Oncology Program (SAOP) 2; CGA: Comprehensive Geriatric Assessment.
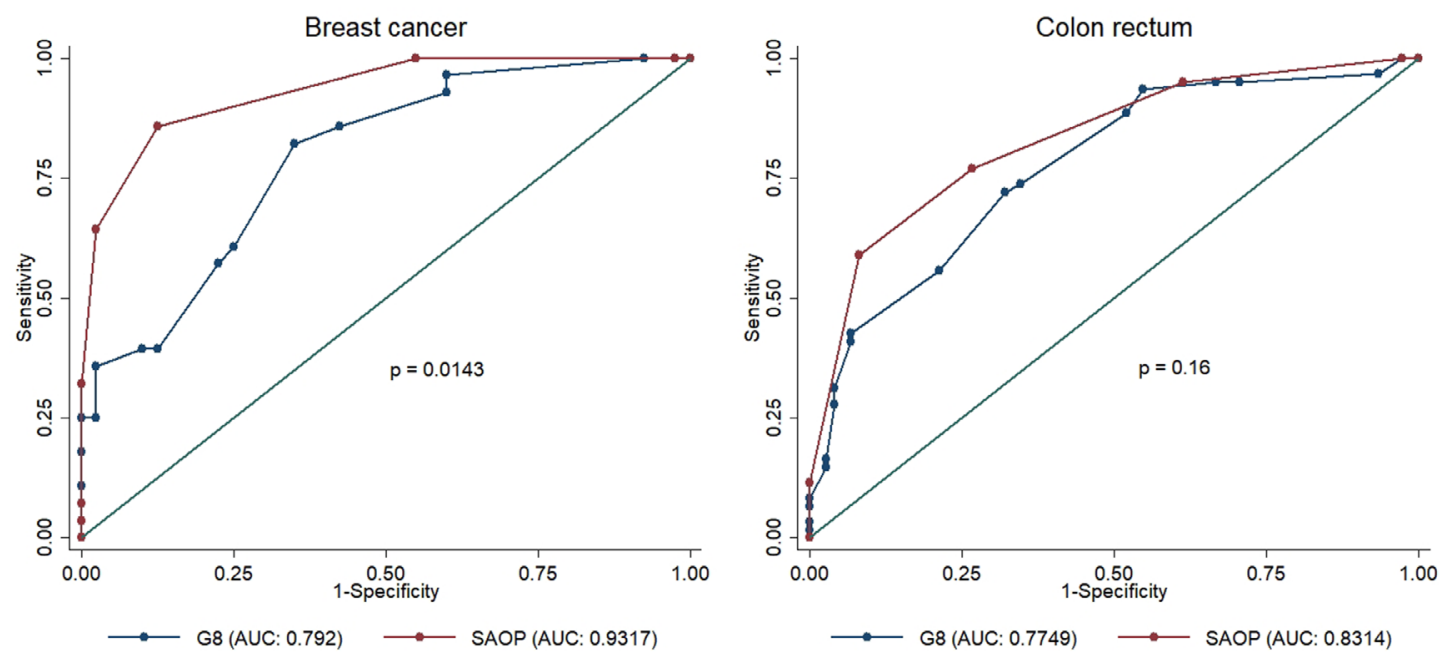

Figure 3: ROC curve comparison of G8 and SAOP2 screening tools in patients with breast cancer and colon rectal cancer respectively. Abbreviations: ROC: Receiver operating characteristic; SAOP2: Senior Adult Oncology Program (SAOP) 2. 
sensitivity in patients with local colorectal cancer, upper digestive, hepatic tumour and in the metastatic group. In keeping with that, Pottel et al [21] has underpinned more impaired G8 scores in patients with advanced cancer, compared to early stage cancer patients.

Thus, it is plausible that subjects with more advanced cancer, and particularly with gastrointestinal and head/neck tumour are frequently comorbid for malnutrition [22], due to the intense inflammatory response associated with anorexia and cachexia [23], which can lead to progressive loss of skeletal muscle mass and worsen impairment of function [24]. Malnutrition has been associated with reduced ability to tolerate anticancer therapy, increased severe dose-limiting toxicities, lesser response rates, worse quality of life, decline in performance status, and shorter survival outcomes [25]. Thus, malnutrition turns to play a key relevant weight in informing G8 impairment.

Indeed, G8 screening tool incorporates most of the MNA items and the fact that MNA was not designed to specifically detect an abnormal CGA may probably explain the lack of specificity of the G8 as a screening instrument [15].

Conversely, in haematological malignancies, the G8 tool didn't adequately discriminate unfit subjects eligible for CGA [26], showing moderate diagnostic accuracy. Hamaker et al [27] has indicated lower sensitivity but better specificity (respectively 69\% and 79\%) of G8 screening performance due to potential higher prevalence of underdiagnosed geriatric syndromes.

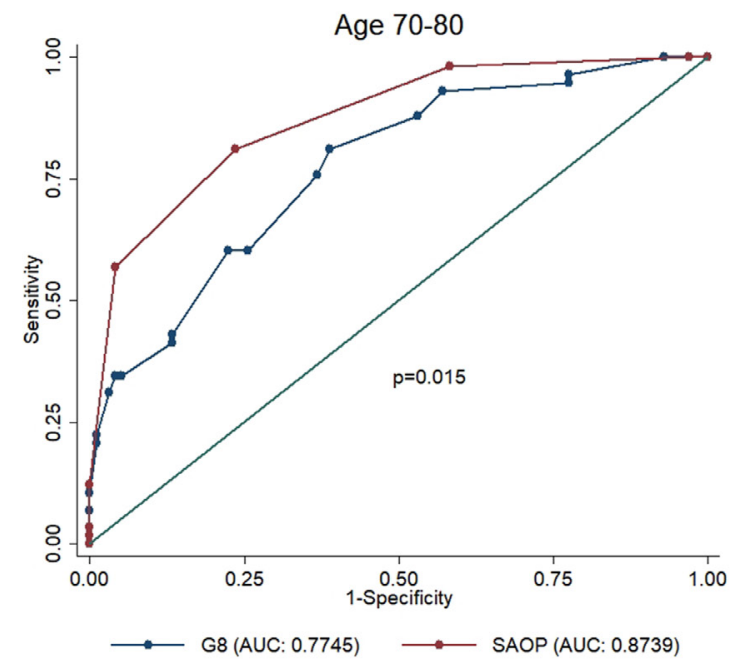

This scientific background may count for the higher accuracy of SAOP2 screening in intercepting vulnerability in breast cancer patients compared to colorectal patients, as observed in the present study.

Thus, different cancer types and stages may have a different weighed impact on screening performance and overall diagnostic accuracy and the use of several validated CGA instruments and cut-off values may also add methodological biases, affecting results reliability.

Fewer evidence has shown the diagnostic accuracy of SAOP2 screening tool in different cancer population and clinical settings. However, SAOP2 tool [28] has shown adequate clinometric properties with reference to the standard geriatric assessment (sensitivity of 100\% and a specificity of 40\%) [29], including the assessment of key relevant issues for cancer related outcomes, such as social vulnerability, depression, quality of life and perceived health status.

Lower perceived social support is generally associated with higher depressive symptoms and lower quality of life [30, 31], especially in cancer patients compared to the general population [30, 32]. Thus, social vulnerability represents a key factor for patient's compliance and the effectiveness of chemotherapy regimens [33, 34]. It has also been shown that social vulnerability and frailty are related but distinct clinical constructs [35] and that the former was a significant predictor of mortality and disability, regardless of patients' frailty [36, 37].

Originally, the present findings indicate SAOP2 better performance in patients aged 70-80 years and

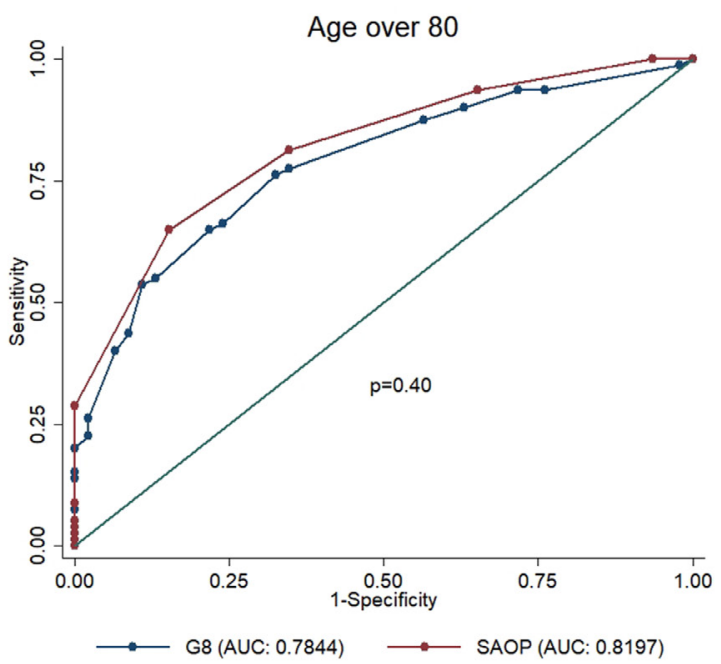

Figure 4: ROC curve comparison of G8 and SAOP2 screening tools in patients aged 70- 80 years and in patients $>80$ years. Abbreviations: ROC: Receiver operating characteristic; SAOP2: Senior Adult Oncology Program (SAOP) 2. 
Table 5: CGA assessment, clinical domain and cut-offs

\begin{tabular}{|c|c|c|c|c|}
\hline Tool & CLINICAL DOMAIN & NUMBER OF ITEMS & RANGE & CUT-OFF * \\
\hline IADL & FUNCTIONAL STATUS & 8 & $0-8$ & $\leq 7$ \\
\hline BARTHEL & FUNCTIONAL STATUS & 10 & $0-100$ & $<50$ \\
\hline MORSE SCALE & RISK OF FALL & 6 & $0-125$ & $\geq 25$ \\
\hline TINETTI SCALE & POSTURAL STABILITY & 16 & $0-28$ & $\leq 18$ \\
\hline $\begin{array}{l}\text { CIRS } \\
\text { SEVERITY } \\
\text { COMORBIDITY }\end{array}$ & COMORBIDITY & 19 & $\begin{array}{c}0-37 \\
0-5 \\
0-13\end{array}$ & $>3$ \\
\hline MMSE & COGNITIVE STATUS & 7 & $0-30$ & $<24$ \\
\hline CDT & COGNITIVE STATUS & 1 & $1-6$ & $\geq 3$ \\
\hline GDS & $\begin{array}{l}\text { PSYCHOLOGICAL } \\
\text { STATUS }\end{array}$ & 15 & $0-15$ & $\geq 5$ \\
\hline MNA & NUTRITIONAL STATUS & 18 & $0-30$ & $<23$ \\
\hline NRS & PAIN & 1 & $0-10$ & $\geq 3$ \\
\hline GIJON SCALE & SOCIAL STATUS & 5 & $5-25$ & $\geq 10$ \\
\hline CGA & - & - & - & $\geq 3$ \\
\hline
\end{tabular}

Abbreviations: I-ADL: Instrumental Activities of Daily Living; CIRS: Cumulative Illness Rating Scale; SI: Illness Severity Index; CI: Co-morbidity Index; MMSE: Mini Mental State Examination; CDT: Clock Drawing Test Shulman; GDS: Geriatric Depression Scale; MNA: Mini Nutritional Assessment; NRS: Numeric Rating Scale; CGA: Comprehensive Geriatric Assessment.

${ }^{*}$ Cut-off score.

support the diagnostic inaccuracy of oncogeriatric screenings (higher false positive screening results) in over octogenarian patients. The biological aging involves a loss of homeostasis with enhanced vulnerability to environmental stressors (surgical interventions or chemotherapy) [33, 38] that may exceed patients' threshold homeostenosis, precipitating a frailty trajectory [39]. Moreover, it is likely that the highly individualized trajectory of frailty could affect the discriminative power of these screening tools, especially in the oldest old ( $>85$ years) populations $[40,41]$. In turn, the time-saving potential of screening may outweigh the risk of incorrectly identifying patients, delivering inappropriate care [41].

On the basis of our results, G8 performance seems to be outweighed by malnutrition risk in cancer patients between 70 and 80 years. Conversely, SAOP2 tool did not show any correlation with GCA domains.

Few studies have addressed the association between single geriatric domains, with reference to CGA assessment, and oncogeriatric screening performance [41]. Namely, Hamaker et al. has shown that G8 had strong predictive ability for malnutrition, but lower predictive value for geriatric conditions. In addition, VES-13 had a fair predictive value for cognitive disorders, impaired mobility, and malnutrition [41]. The association of screening tools with social support, showed a very low diagnostic accuracy (VES-13 sensitivity 33\%; specificity 46\%) [41-44].
In our population, SAOP2 was not statistically associated with social domains even an association trend with poorer perceived health status and lack of support was observed. This may be due to the partial diagnostic accuracy of the used Gijon Scale; in turn, the social vulnerability index (SVI) [36], may be the most appropriate tool in elderly cancer patients. However, the lack of any Italian validation hampers the feasibility of such a tool in intercepting patients' social vulnerability.

Even preliminary in nature, SAOP2 tool seems to better predict clinical vulnerability, especially at the earlier stages of cancer. This is particularly true in "younger" patients with two wide prevalent cancer types.

The present study has some limitations. First, nonmetastatic colorectal and breast cancer were strongly represented while patients with progression/relapse of the disease were systematically excluded. Thus, stratification of patients with different cancer types and stages is still needed. Moreover, the single centre population may represent a potential bias selection.

Notwithstanding that, the strength of the study lies on the real-world assessment of an oncogeriatric population, with the direct comparison of G8 and SAOP2 screening accuracy. Assessing this aspect would warrant more sophisticated study designs, including the feedback of a GA team, the appropriateness of the referral and the time frame of clinical interventions. In line with that, 
the prospective nature of the present study will help the understating of outcome measures in terms of service utilization, geriatric referrals, complications, functional independence and survival variables.

Comparing sensitivity and specificity to CGA has the advantage of feasibility in a study. However, it only indirectly addresses the question of how useful the tool is for selecting patients. Therefore, which screening tool could best suit the older cancer populations is a matter of debate. The inclusion of frailty indicators and biological markers may add knowledge to this intriguing field and is part of the observational study.

Eventually, further research is needed to optimize the use of SAOP2 screening tool. On the basis of its multidisciplinary nature and the inclusion of key relevant issues like social vulnerability, health perceived status and quality of life, it has great potential of defining clinical pathways, targeting the quality of life and the quality of care in this outgrowing number of cancer patients [15].

\section{MATERIALS AND METHODS}

\section{Study design and population}

This prospective study was performed at the Ospedale Policlinico San Martino, Genoa, Italy, from January 2015 to May 2017.

Inclusion criteria were all patients over 65 years with a first diagnosis of solid tumour, who qualified for surgery and/or chemotherapy, adequate understanding of the Italian language and ability to sign an informed consent.

Exclusion criteria were: palliative care patients; severe dementia or pre-existing major neurological and/ or psychiatric disorders.

The study was approved by the ethical committee of the participating hospital, and written informed consent was obtained by all subjects or their next to kin.

Patients were simultaneously tested for G8 and SAOP2 questionnaire and comprehensive geriatric assessment, before oncological treatment (surgery, neoadjuvant or adjuvant chemotherapy), by an expert geriatrician.

First visit also included the Short Form 36 [45, 46] to assess quality of life.

Demographic data (age, gender), tumour characteristics (site, local or metastatic), proposed chemotherapy and/or surgery, geriatric recommended clinical interventions were also collected.

\section{Test methods}

\section{G8 screening tool}

The G8 screening tool was developed to identify elderly unfit cancer patients, eligible for geriatric assessment.

The G8 test consists of the following eight items: chronological age $(<80,80-85,>85$ years $)$ and seven clinical items including the Mini Nutritional Assessment, a questionnaire dealing with food intake, weight loss, mobility, neuropsychological comorbidity, body mass index, prescription drug, and self-perception of health status $[1,22,40]$.

The total score can range from 0 to 17 . A score of $\leq 14$ is considered abnormal, indicating a clinical vulnerability profile. (Supplementary Appendix 1)

The G8 was compared in terms of clinometric properties with CGA in eight different studies, that cumulatively included 3816 patients [13, 16-20, 40, 47]. Sensitivity ranged from $65 \%$ to $92 \%$, specificity ranged from $3 \%$ to $75 \%$ and negative predictive value (NPV) from $8 \%$ to $78 \%$ [9].

\section{Senior adult oncology program (SAOP) 2}

The SAOP2 screening tool was developed by the multidisciplinary clinical team of the SAOP at Moffitt Cancer Centre [10]. In addition to functional status, depression, and cognitive screening, the tool includes the assessment of health-related quality of life, self-rated health, falls, nutrition, sleep, multiple medications, and social issues (drug payment and reimbursement and caregiver availability) (Supplementary File 2) [10].

If 1 item is impaired, the respective specialist is called in, with potential secondary referral to other team members. If several items are impaired, the multidisciplinary team is called along with the geriatric referral for CGA assessment. SAOP2 is a sensitive tool, with low internal specificity, addressing the importance of a multidisciplinary team approach $[28,29,48]$.

\section{Comprehensive geriatric assessment (CGA)}

An expert geriatrician administered the CGA assessment in an average time of 50 minutes. It evaluates the following tools to assess several clinical domains (Table 5): cognitive status (Mini Mental State Examination, MMSE [49] and Clock Drawing Test, CDT [50]), psychological status (Geriatric Depression scale, GDS 15 items [51]), functional status (Instrumental Activities of Daily Living, IADL, of Lawton [52] and Barthel Index [53]), postural stability (Tinetti Scale [54]), risk of falls (Morse Scale [55]), physical performance (Timed "Up \& Go" test, TUG [56, 57]), nutritional status (Mini Nutritional Assessment [58]), social vulnerability (Gijon Scale [59]), physical burden of illness (Cumulative Illness Rating Scale, CIRS: Illness Severity Index-SI, and Co-morbidity Index-CI $[60,61])$. Patients were categorized as impaired if the $\mathrm{CGA} \geq 3$ deficits [62].

Pain was assessed using the Numeric Rating Scale (NRS) $[63,64]$. Polypharmacy was also collected. 


\section{Outcome}

The primary outcome was to assess the diagnostic accuracy of SAOP2 and G8 screening tool, with reference to CGA, in detecting patient's clinical vulnerability.

\section{Statistical analysis}

The descriptive analysis for quantitative variables was expressed as mean and standard deviation (SD) or median and interquartile range (IQR).

Sensitivity and specificity of both screening tools were calculated using the pre-specified cut-offs from literature.

Further receiver operating characteristic (ROC) curves were used to compare G8 and SAOP2 screening tools.

If present, indeterminate results were considered as false-positive or false-negative and incorporated into the final analysis. For example, an indeterminate result in a patient found to be frailty according to CGA was considered to have had a negative test result.

Area under the curves (AUC) with 95\% CI were reported. AUCs were compared using chi-square test.

A non-parametric Mann-Whitney test was used to compare two variable.

A p-value $<0.05$ was considered statistically significant.

Stata (v.14; function "roccomp"; StataCorp) was used for the computation.

\section{Abbreviations}

CGA: Comprehensive Geriatric Assessment; SIOG: International Society of Geriatric Oncology; NCCN:National Comprehensive Cancer Network; EORTC:European Organization for Research and Treatment of Cancer; SAOP2:Senior Adult Oncology Program (SAOP) 2; OGS:Oncogeriatric screen; aCGA:Abbreviated Comprehensive; VES-13: Vulnerable Elders Survey-13; fTRST: Flemish version of the Triage Risk Screening Tool; GFI:Groninger Frailty Index; IR:Rockwood Index; SF36:Short Form 36; MNA:Mini Nutritional Assessment; GA:geriatric assessment; NPV:negative predictive value; MMSE: Mini Mental State Examination; CDT:Clock Drawing Test Shulman; GDS:Geriatric Depression Scale; I-ADL:Instrumental Activities of Daily Living; TUG:Timed "Up \& Go" test; CIRS:Cumulative Illness Rating Scale; SI:Illness Severity Index; CI:Co-morbidity Index; NRS: Numeric Rating Scale; SVI:social vulnerability index; CTCAE: National Cancer Institute Common Terminology Criteria for Adverse Events; SD:standard deviation; IQR:median and interquartile range; AUC:Area under the curves; ROC:Receiver operating characteristic.

\section{Author contributions}

Study Concepts and design: CR, AN, PO, FM. Collection and assembly of data: CR, CG, SS, ER, $\mathrm{RM}, \mathrm{AB}$.

Data analysis and interpretation: CR, CG, FM.

Statistical analysis: CG, AS, FM.

Manuscript writing: CR, CG, FM, AN.

\section{ACKNOWLEDGMENTS}

This work was supported in part by the Associazione Italiana per la Ricerca sul Cancro (AIRC, \#17736, to A. N.), by the Seventh Framework Program project ATHERO-B-CELL (\#602114; to A. N.), by the Fondazione Umberto Veronesi (to A. N.); by the Italian Ministry of Health (PE-2016-02363073; to F.M.), by the $5 \times 10002014$ Funds to the IRCCS San Martino-IST (to A. N. and to M.C.) and by the University of Genoa.

\section{CONFLICTS OF INTEREST}

The authors have no conflicts of interest to disclose.

\section{REFERENCES}

1. Petit-Monéger A, Rainfray M, Soubeyran P, Bellera CA, Mathoulin-Pélissier S. Detection of frailty in elderly cancer patients: Improvement of the G8 screening test. J Geriatr Oncol. 2016; 7:99-107.

2. Surveillance, Epidemiology, and End Results: SEER Cancer Statistics Review, 1975-2010.

3. de Martel C, Ferlay J, Franceschi S, Vignat J, Bray F, Forman D, Plummer M. Global burden of cancers attributable to infections in 2008: a review and synthetic analysis. Lancet Oncol. 2012; 13:607-15.

4. Yancik R. Cancer burden in the aged: an epidemiologic and demographic overview. Cancer. 1997; 80:1273-1283.

5. Extermann M, Aapro M, Bernabei R, Cohen HJ, Droz JP, Lichtman S, Mor V, Monfardini S, Repetto L, Sørbye L, Topinkova E, and Task Force on CGA of the International Society of Geriatric Oncology. Use of comprehensive geriatric assessment in older cancer patients: Recommendations from the task force on CGA of the International Society of Geriatric Oncology (SIOG). Crit Rev Oncol Hematol. 2005; 55:241-52.

6. Martinez-Tapia C, Paillaud E, Liuu E, Tournigand C, Ibrahim R, Fossey-Diaz V, Culine S, Canoui-Poitrine F, Audureau E, Caillet P, Laurent M, Paillaud E, Tournigand C, et al, and ELCAPA Study Group. Prognostic value of the G8 and modified-G8 screening tools for multidimensional health problems in older patients with cancer. Eur J Cancer. 2017; 83:211-219.

7. Hurria A, Wildes T, Blair SL, Browner IS, Cohen HJ, Deshazo M, Dotan E, Edil BH, Extermann M, Ganti AK, 
Holmes HM, Jagsi R, Karlekar MB, et al. Senior adult oncology, version 2.2014: clinical practice guidelines in oncology. J Natl Compr Canc Netw. 2014; 12:82-126.

8. Pallis AG, Papamichael D, Audisio R, Peeters M, Folprecht G, Lacombe D, Van Cutsem E. EORTC Elderly Task Force experts' opinion for the treatment of colon cancer in older patients. Cancer Treat Rev. 2010; 36:83-90.

9. Decoster L, Van Puyvelde K, Mohile S, Wedding U, Basso U, Colloca G, Rostoft S, Overcash J, Wildiers H, Steer C, Kimmick G, Kanesvaran R, Luciani A, et al. Screening tools for multidimensional health problems warranting a geriatric assessment in older cancer patients: an update on SIOG recommendations. Ann Oncol. 2015; 26:288-300.

10. Extermann M. Integrating a geriatric evaluation in the clinical setting. Semin Radiat Oncol. 2012; 22:272-276.

11. Extermann M. Basic assessment of the older cancer patient. Curr Treat Options Oncol. 2011; 12:276-285.

12. Fagard K, Casaer J, Wolthuis A, Flamaing J, Milisen K, Lobelle JP, Wildiers H, Kenis C. Value of geriatric screening and assessment in predicting postoperative complications in patients older than 70 years undergoing surgery for colorectal cancer. J Geriatr Oncol. 2017; 8:320-32.

13. Kenis C, Decoster L, Van Puyvelde K, De Grève J, Conings G, Milisen K, Flamaing J, Lobelle JP, Wildiers H. Performance of two geriatric screening tools in older patients with cancer. J Clin Oncol. 2014; 32:19-26.

14. Kenig J, Zychiewicz B, Olszewska U, Richter P. Screening for frailty among older patients with cancer that qualify for abdominal surgery. J Geriatr Oncol. 2015; 6:52-9.

15. Martinez-Tapia C, Canoui-Poitrine F, Bastuji-Garin S, Soubeyran P, Mathoulin-Pelissier S, Tournigand C, Paillaud E, Laurent M, Audureau E, and ELCAPA Study Group. Optimizing the G8 Screening Tool for Older Patients With Cancer: Diagnostic Performance and Validation of a SixItem Version. Oncologist. 2016; 21:188-95.

16. Soubeyran P, Bellera C, Goyard J, Heitz D, Curé H, Rousselot H, Albrand G, Servent V, Jean OS, van Praagh I, Kurtz JE, Périn S, Verhaeghe JL, et al. Screening for vulnerability in older cancer patients: the ONCODAGE Prospective Multicenter Cohort Study. PLoS One. 2014; 9:e115060.

17. Kenis C, Schuermans H, Van Cutsem E, Verhoef G, Vansteenkiste J, Vergote I, Schoffski P, Milisen K, Flamaing J, Wildiers H. Screening for a geriatric risk profile in older cancer patients: a comparative study of the predictive validity of three screening tools. Crit Rev Oncol Hematol. 2009; 72:S22.

18. Baitar A, Van Fraeyenhove F, Vandebroek A, De Droogh E, Galdermans D, Mebis J, Schrijvers D. Evaluation of the Groningen Frailty Indicator and the G8 questionnaire as screening tools for frailty in older patients with cancer. $\mathrm{J}$ Geriatr Oncol. 2013; 4:32-8.

19. Pottel L, Boterberg T, Pottel H, Goethals L, Van Den Noortgate N, Duprez F, De Neve W, Rottey S, Geldhof K,
Van Eygen K, Kargar-Samani K, Ghekiere V, Cornelis F, et al. Determination of an adequate screening tool for the identification of vulnerable elderly head and neck cancer patients treated with radio(chemo)therapy. J Geriatr Oncol. 2012; 3:24-32.

20. Liuu E, Canoui-Poitrine F, Tournigand C, Laurent M, Chaubet M, Caillet P, Le Thuaut A, Vincent H, Culine S, Paillaud E for the ELCAPA Study Group. External validation of the G8 geriatric screening tool to identify vulnerable elderly cancer patients: the ELCAPA-02 study. J Geriatr Oncol. 2012; 3:S45.

21. Pottel L, Lycke M, Boterberg T, Pottel H, Goethals L, Duprez F, Rottey S, Lievens Y, Van Den Noortgate N, Geldhof K, Buyse V, Kargar-Samani K, Ghekiere V, Debruyne PR. G-8 indicates overall and quality-adjusted survival in older head and neck cancer patients treated with curative radiochemotherapy. BMC Cancer. 2015; 15:875.

22. Takahashi M, Takahashi M, Komine K, Yamada H, Kasahara Y, Chikamatsu S, Okita A, Ito S, Ouchi K, Okada Y, Imai H, Saijo K, Shirota H, et al. The G8 screening tool enhances prognostic value to ECOG performance status in elderly cancer patients: A retrospective, single institutional study. PLoS One. 2017; 12:e0179694.

23. Muscaritoli M, Lucia S, Farcomeni A, Lorusso V, Saracino V, Barone C, Plastino F, Gori S, Magarotto R, Carteni G, Chiurazzi B, Pavese I, Marchetti L, et al, and PreMiO Study Group. Prevalence of malnutrition in patients at first medical oncology visit: the PreMiO study. Oncotarget. 2017; 8:79884-96. https://doi.org/10.18632/ oncotarget.20168.

24. Laviano A, Koverech A, Mari A. Cachexia: clinical features when inflammation drives malnutrition. Proc Nutr Soc. 2015; 74:348-354.

25. Mislang AR, Di Donato S, Hubbard J, Krishna L, Mottino G, Bozzetti F, Biganzoli L. Nutritional management of older adults with gastrointestinal cancers: An International Society of Geriatric Oncology (SIOG) review paper. J Geriatr Oncol. 2018; 9:382-392.

26. Dubruille S, Libert Y, Roos M, Vandenbossche S, Collard A, Meule man N, Maerevoet M, Etienne AM, Reynaert C, Razavi D, Bron D. Identification of clinical parameters predictive of one-year survival using two geriatric tools in clinically fit older patients with hematological malignancies: Major impact of cognition. J Geriatr Oncol. 2015; 6:362-9.

27. Hamaker ME, Mitrovic M, Stauder R. The G8 screening tool detects relevant geriatric impairments and predicts survival in elderly patients with a haematological malignancy. Ann Hematol. 2014; 93:1031-40.

28. Extermann M. Evaluation of the Senior Cancer Patient: Comprehensive Geriatric Assessment and Screening Tools for the Elderly. In: Schrijvers D, Aapro M, Zakotnik B, Audisio R, van Halteren H, Hurria A, Eds., Handbook of Cancer in the Senior Patient. New York, London: Informa Healthcare; 2010. pp 13-21. 
29. Extermann M, Green T, Tiffenberg G, Rich CJ. Validation of the Senior Adult Oncology Program (SAOP) 2 screening questionnaire. Crit Rev Oncol Hematol. 2009; 69:185.

30. Yoo H, Shin DW, Jeong A, Kim SY, Yang HK, Kim JS, Lee JE, Oh JH, Park EC, Park K, Park JH. Perceived social support and its impact on depression and health-related quality of life: a comparison between cancer patients and general population. Jpn J Clin Oncol. 2017; 47:728-734.

31. Lachman ME, Agrigoroaei S. Promoting functional health in midlife and old age: long-term protective effects of control beliefs, social support, and physical exercise. PloS One. 2010; 5:e13297.

32. Azuero A, Benz R, McNees P, Meneses K. Co-morbidity and predictors of health status in older rural breast cancer survivors. Springerplus. 2014; 3:102.

33. Balducci L, Colloca G, Cesari M, Gambassi G. Assessment and treatment of elderly patients with cancer. Surg Oncol. 2010; 19:117-23.

34. Kubzansky LD, Berkman LF, Seeman TE. Social conditions and distress in elderly persons: findings from the MacArthur Studies of Successful Aging. J Gerontol B Psychol Sci Soc Sci. 2000; 55:P238-46.

35. Andrew MK, Mitnitski AB, Rockwood K. Social vulnerability, frailty and mortality in elderly people. PLoS One. 2008; 3:e2232.

36. Wallace LM, Theou O, Pena F, Rockwood K, Andrew MK. Social vulnerability as predictor of mortality and disability: cross-country differences in the survey of health, aging, and retirement in Europe (SHARE). Aging Clin Exp Res. 2015; 27:365-72.

37. Andrew MK, Mitnitski A, Kirkland S, Rockwood K. The impact of social vulnerability on the survival of the fittest older adults. Age Ageing. 2012; 41:161-65.

38. Balducci L, Extermann M. Management of cancer in the older person: a practical approach. Oncologist. 2000; 5:224-37.

39. Colloca G, Corsonello A, Marzetti E, Balducci L, Landi F, Extermann M, Scambia G, Cesari M, Carreca I, Monfardini $\mathrm{S}$, Bernabei R. Treating cancer in older and oldest old patients. Curr Pharm Des. 2015; 21:1699-705.

40. Bellera CA, Rainfray M, Mathoulin-Pélissier S, Mertens C, Delva F, Fonck M, Soubeyran PL. Screening older cancer patients: first evaluation of the G-8 geriatric screening tool. Ann Oncol. 2012; 23:2166-72.

41. Hamaker ME, Jonker JM, de Rooij SE, Vos AG, Smorenburg $\mathrm{CH}$, van Munster BC. Frailty screening methods for predicting outcome of a comprehensive geriatric assessment in elderly patients with cancer: a systematic review. Lancet Oncol. 2012; 13:37-44.

42. Owusu C, Koroukian SM, Schluchter M, Bakaki P, Berger NA. Screening older cancer patients for a Comprehensive Geriatric Assessment: a comparison of three instruments. J Geriatr Oncol. 2011; 2:121-129.
43. Mohile SG, Bylow K, Stadler WW, Rodin M. A pilot study of the Vulnerable Elders Survey (VES-13) as compared to Comprehensive Geriatric Assessment (CGA) to examine geriatric domains in elder prostate cancer patients at risk for decline. J Clin Oncol. 2006; 24:8539.

44. Mohile SG, Bylow K, Dale W, Dignam J, Martin K, Petrylak DP, Stadler WM, Rodin M. A pilot study of the vulnerable elders survey-13 compared with the comprehensive geriatric assessment for identifying disability in older patients with prostate cancer who receive androgen ablation. Cancer. 2007; 109:802-10.

45. McHorney CA, Ware JE Jr, Raczek AE. The MOS 36-Item Short- Form Health Survey (SF-36): II. Psychometric and clinical tests of validity in measuring physical and mental health constructs. Med Care. 1993; 31:247-63.

46. Ware JE Jr, Sherbourne CD. The MOS 36-item short-form health survey (SF-36). I. Conceptual framework and item selection. Med Care. 1992; 30:473-83.

47. Luce S, De Breucker S, Van Gossum Au, Demols A, Mekinda Z, Ena G, Kentos A, Roumèguere T, Ghanooni R, Nouwynck C, Van Laethem JL, Sokolow Y, Simon P, et al. How to identify older patients with cancer who should benefit from comprehensive geriatric assessment. J Geriatr Oncol 2012; 3:351-358.

48. Johnson D, Blair J, Balducci L, Extermann M, Crocker T, McGinnis M, Vranas P. The assessment of clinical resources in a senior adult oncology program. European Oncology Nursing Society Meeting, Innsbruck, Austria, 2006.

49. Folstein MF, Folstein SE, McHugh PR. "Mini-mental state". A practical method for grading the cognitive state of patients for the clinician. J Psychiatr Res. 1975; 12:189-98.

50. Shulman KI. Clock-drawing: Is it the ideal cognitive screening test? Int J Geriatr Psychiatry. 2000; 15:548-61.

51. Yesavage JA, Brink TL, Rose TL, Lum O, Huang V, Adey M, Leirer VO. Development and validation of a geriatric depression screening scale: a preliminary report. J Psychiatr Res. 1982; 17:37-49.

52. Lawton MP, Brody EM. Assessment of older people: selfmaintaining and instrumental activities of daily living. Gerontologist. 1969; 9:179-86.

53. Mahoney FI, Barthel DW. Functional evaluation: the Barthel Index. Md State Med J. 1965; 14:61-5.

54. Köpke S, Meyer G. The Tinetti test: Babylon in geriatric assessment. Z Gerontol Geriatr. 2006; 39:288-91.

55. Morse JM. Predicting fall risk. Can J Nurs Res. 1998; 30:11-2.

56. Mathias S, Nayak US, Isaacs B. Balance in elderly patients: the "get-up and go" test. Arch Phys Med Rehabil. 1986; 67:387-9.

57. Podsiadlo D, Richardson S. The timed "Up \& Go": a test of basic functional mobility for frail elderly persons. J Am Geriatr Soc. 1991; 39:142-8.

58. Guigoz Y, Vellas B. The Mini Nutritional Assessment (MNA) for grading the nutritional state of elderly patients: 
presentation of the MNA, history and validation. Nestle Nutr Workshop Ser Clin Perform Programme 1999; 1:3-11.

59. García González JV, Díaz Palacios E, Salamea García A, Cabrera González D, Menéndez Caicoya A, Fernández Sánchez A, Acebal García V. An evaluation of the feasibility and validity of a scale of social assessment of the elderly. Aten Primaria. 1999; 23:434-40.

60. Linn BS, Linn MW, Gurel L. Cumulative illness rating scale. J Am Geriatr Soc. 1968; 16:622-6.

61. Rochon PA, Katz JN, Morrow LA, McGlinchey-Berroth R, Ahlquist MM, Sarkarati M, Minaker KL. Comorbid illness is associated with survival and length of hospital stay in patients witz chronic disability. A prospective comparison of three comorbidity indices. Med Care. 1996; 34:1093-101.
62. Handforth C, Clegg A, Young C, Simpkins S, Seymour MT, Selby PJ, Young J. The prevalence and outcomes of frailty in older cancer patients: a systematic review. Ann Oncol. 2015; 26:1091-101.

63. Paice JA, Cohen FL. Validity of a verbally administered numeric rating scale to measure cancer pain intensity. Cancer Nurs. 1997; 20:88-93.

64. Hjermstad MJ, Fayers PM, Haugen DF, Caraceni A, Hanks GW, Loge JH, Fainsinger R, Aass N, Kaasa S; European Palliative Care Research Collaborative (EPCRC). Studies comparing Numerical Rating Scales, Verbal Rating Scales, and Visual Analogue Scales for assessment of pain intensity in adults: a systematic literature review. J Pain Symptom Manage. 2011; 41:1073-93. 